\title{
THE VAPOUR PRESSURE AND OSMOTIC EQUIVALENCE OF SEA WATER
}

\author{
By R. A. Robinson, D.Sc., F.R.I.C. \\ Professor of Chemistry, University of Malaya, Singapore
}

Sea water is a complex solution in which the principal ions are sodium, potassium, calcium, magnesium, chloride and sulphate. The vapour pressure (v.P.) of such a solution can be calculated approximately by making the assumption that each salt contributes to the vapour pressure lowering in amount proportional to its concentration, but such a calculation would ignore the interactions between the various ions. The theory of these interactions has been worked out only for very dilute solutions and it is, therefore, better to rely on direct experimental determinations. Measurements have now been made by the isopiestic vapour-pressure method (Robinson \& Sinclair, I934), in which samples of sea water are equilibrated with sodium chloride solutions until they have the same vapour pressure. The results are expressed in terms of chlorinities of sea water and molalities (moles per kilogram of $\mathrm{H}_{2} \mathrm{O}$ ) of sodium chloride solution which have the same vapour pressure. It is hoped that the results will be of use to physiologists who have occasion to make up salt solutions equivalent to sea water.

\section{EXPERIMENTAL}

Three samples of sea water were used:

(I) Eau de mer normale, $\mathrm{P}_{17}, 3 \mathrm{I}$ October $1948, \% \mathrm{Cl}=19.386$; found by gravimetric analysis, $19.408 \%{ }^{\star}$ (i.e. by precipitation as silver halide, calculated as silver chloride).

(2) An artificial sea water made up as follows:

$\begin{array}{lclc} & \mathrm{g} / \mathrm{kg} & & \mathrm{g} / \mathrm{kg} \\ \text { solution } & & \text { Solution } \\ \text { Sodium chloride } & 28 \cdot 85 & \text { Calcium chloride } & \mathrm{I} \cdot 244 \\ \text { Potassium chloride } & 0.8 \mathrm{II} & \text { Magnesium sulphate } & 3.649 \\ \text { Magnesium chloride } & 2.633 & & \end{array}$

The composition is quoted in terms of anhydrous salt. Found by titration against Eau de mer normale: $\% \mathrm{Cl}=20 \cdot 58$; by gravimetric analysis : $20 \cdot 62$.

(3) Sea water taken from the Straits of Singapore. Found by titration against Eau de mer normale: $\% \mathrm{Cl}=17 \cdot 27$; by gravimetric analysis: $17 \cdot 35$.

* This figure includes the weight of bromine in excess of the equivalent of chlorine. If allowance is made for this, and the new figure divided by $\mathrm{I} \cdot 00045$ to allow for change in atomic weights since 1937 , the gravimetric chlorinity becomes $19 \cdot 390 \%$. Similarly the gravimetric chlorinities of samples 2 and 3 become $20.60 \%$ and $17.33 \%$, agreeing with the titration chlorinities even better than the author claims.-(Ed.) 
The densities of these three solutions were found to be $d_{4}^{25}=\mathrm{I} \cdot 0233_{4}$, $\mathrm{I} \cdot 02498$ and $\mathrm{I} \cdot 0206_{2}$ respectively. The results of this investigation are all expressed in terms of chlorinities as found by titration.

In the isopiestic method samples of sea water are weighed in two platinum dishes, and samples of a $\mathrm{NaCl}$ solution of known composition are weighed out into two other platinum dishes. The four dishes are then placed on a copper block in a desiccator which is evacuated and rocked gently in a thermostat at $25^{\circ} \mathrm{C}$ for 2 days. During this interval water distils from one solution to another until equilibrium is reached when the concentrations of all four solutions are such that the vapour pressures of all four are equal. The dishes are then weighed again and, from the loss or gain in weight, the final concentrations of the solutions are calculated. These solutions of equal vapour pressure are said to be isopiestic and the ratio, $R$, of the concentration of the sodium chloride solution to that of the sea water is called the isopiestic ratio. If the vapour pressures of solutions of sodium chloride are known as a function of their concentration, and tables of such vapour pressures have been published (Robinson, 1945; Stokes \& Levien, 1946), then the vapour pressure of the sample of sea water can be calculated for a particular concentration. Thus, in one experiment, a sea-water solution of $20.02 \%$ chlorinity was found to have the same v.P. as $0.5889 \mathrm{M}-\mathrm{NaCl}$ solution; the relative molal v.P. lowering of $\mathrm{NaCl},\left(p^{0}-p\right) / m p^{0}$, where $p^{0}$ is the v.P. of pure water and $p$ is the v.P. of $\mathrm{NaCl}$ solution of molality $m$, is 0.03290 at $0.5 \mathrm{M}$ and 0.03292 at $0.6 \mathrm{M}$. It may be taken as 0.03292 at $0.5889 \mathrm{M}$ and the relative vapour pressure lowering $\left(p^{0}-p\right) / p^{0}$ or $\Delta p / p^{0}$, as $0.03292 \times 0.5889=0.01939$. If the v.P. is required we put $p^{\circ}=23.756 \mathrm{~mm}$ at $25^{\circ}$ so that $\left(p^{0}-p\right)=0.46 \mathrm{Imm}$ and $p=23.295 \mathrm{~mm}$. This is also the v.P. of $20.02 \% \mathrm{Cl}$ sea water.

The experiment is repeated at a number of different concentrations to investigate the change in v.P. over a range of concentrations. Fourteen measurements were made using the three sea-water samples and the results are given in Table I. Over the range $9-22 \% \mathrm{Cl}$, the ratio of $\mathrm{NaCl}$ molality to sea-water chlorinity can be expressed as

$$
R=0.02782+0.000079(\% \mathrm{Cl}),
$$

a formula which expresses the results in Table I with an average deviation of $0.18 \%$.

\section{Discussion}

The above equation can be used to calculate values of $R$ at round values of the chlorinity between IO and $22 \%$. These are recorded in Table II. The third column of the table gives the molality of $\mathrm{NaCl}$ solution of the same v.P. as the sea water whose chlorinity is given in the first column. A very careful study has been made (Robinson, I945) of the ratio of the molalities of $\mathrm{NaCl}$ and $\mathrm{KCl}$ solutions which are isopiestic (i.e. have the same v.P.), and it is therefore possible to give in the fourth column the molalities of $\mathrm{KCl}$ solutions 
Table I. Molalities of Sodium Chloride Solutions and Chlorinities of Sea Water of the same Vapour Pressure

\begin{tabular}{|c|c|c|c|c|}
\hline \multirow[b]{2}{*}{ Sample } & \multirow[b]{2}{*}{$\mathrm{M}-\mathrm{NaCl}$} & \multirow[b]{2}{*}{$\% \mathrm{Cl}$} & \multicolumn{2}{|c|}{$R$} \\
\hline & & & Observed & Calculated \\
\hline \multirow[t]{4}{*}{ I } & 0.4296 & I 4.79 & 0.02905 & 0.02899 \\
\hline & 0.5454 & 18.62 & 0.02929 & 0.02929 \\
\hline & 0.5847 & 19.90 & 0.02938 & 0.02939 \\
\hline & 0.6185 & $2 \mathrm{I} \cdot \mathrm{OI}$ & 0.02944 & 0.02948 \\
\hline \multirow[t]{8}{*}{2} & 0.2700 & 9.44 & 0.02860 & 0.02857 \\
\hline & 0.3774 & 13.08 & 0.02885 & 0.02885 \\
\hline & 0.4220 & 14.60 & 0.02890 & 0.02897 \\
\hline & 0.4350 & $15 \cdot 04$ & 0.02892 & 0.02900 \\
\hline & 0.4737 & 16.35 & 0.02897 & 0.02911 \\
\hline & 0.5492 & $18 \cdot 72$ & 0.02934 & 0.02930 \\
\hline & 0.5889 & $20 \cdot 02$ & 0.02942 & 0.02940 \\
\hline & $0.617 \mathrm{I}$ & 20.96 & 0.02944 & 0.02948 \\
\hline \multirow[t]{2}{*}{3} & 0.4628 & I5.87 & 0.02916 & 0.02907 \\
\hline & 0.5753 & 19.52 & 0.02947 & 0.02936 \\
\hline
\end{tabular}

Table II. Vapour Pressure and Osmotic Equivalence of Sea Water at $25^{\circ} \mathrm{C}$

\begin{tabular}{|c|c|c|c|c|c|c|c|c|c|c|c|}
\hline$\% \mathrm{Cl}$ & $R$ & $\mathrm{NaCl}$ & $\mathrm{KCl}$ & $\mathrm{CaCl}_{2}$ & $\mathrm{MgCl}_{2}$ & $\mathrm{MgSO}_{4}$ & $\mathrm{Na}_{2} \mathrm{SO}_{4}$ & Sucrose & Urea & $\begin{array}{c}\text { V.P. } \\
\text { lowering }\end{array}$ & $\begin{array}{c}\text { Osmotic } \\
\text { pressure } \\
\text { (atm.) }\end{array}$ \\
\hline Io & $0.0286 \mathrm{I}$ & $0.286 \mathrm{I}$ & 0.2908 & 0.2039 & 0.2005 & 0.5056 & 0.2374 & 0.5065 & 0.5400 & 0.00946 & I 2.87 \\
\hline II & 0.02869 & 0.3156 & $0.32 \mathrm{II}$ & 0.2240 & 0.2199 & 0.5597 & 0.2643 & 0.5560 & 0.5965 & 0.01042 & I4. I9 \\
\hline 12 & 0.02877 & 0.3452 & 0.3516 & $0.244 \mathrm{I}$ & 0.2393 & 0.6138 & 0.2918 & 0.6053 & 0.6534 & 0.01139 & 15.51 \\
\hline I3 & 0.02885 & $0.375 \mathrm{I}$ & 0.3825 & 0.2642 & 0.2588 & 0.6675 & 0.3196 & 0.6546 & $0.7 \mathrm{II2}$ & 0.01237 & 16.85 \\
\hline I4 & 0.02893 & 0.4050 & 0.4134 & $0.284 \mathrm{I}$ & 0.2780 & 0.7206 & 0.3477 & 0.7040 & 0.7695 & 0.01334 & I8. I9 \\
\hline I5 & 0.02901 & 0.4352 & 0.4447 & 0.3043 & 0.2975 & $0.773^{8}$ & 0.3762 & 0.7534 & 0.8285 & 0.01433 & 19.55 \\
\hline 16 & 0.02908 & 0.4653 & 0.4760 & 0.3243 & 0.3165 & 0.8264 & 0.4051 & 0.8025 & 0.8880 & 0.01532 & 20.91 \\
\hline I7 & 0.02916 & 0.4957 & 0.5077 & 0.3445 & 0.3356 & 0.8786 & 0.4347 & 0.8516 & 0.9482 & 0.01631 & $22 \cdot 28$ \\
\hline I8 & 0.02924 & 0.5263 & 0.5397 & 0.3645 & 0.3546 & 0.9300 & 0.4648 & 0.9008 & I.OIO & 0.01732 & 23.66 \\
\hline I9 & 0.02932 & $0.557 \mathrm{I}$ & 0.5719 & 0.3845 & $0.373^{8}$ & 0.9803 & 0.4954 & 0.9497 & I.07I & 0.01833 & 25.06 \\
\hline 20 & 0.02940 & 0.5880 & 0.6043 & 0.4044 & 0.3929 & $\mathrm{I} \cdot 028$ & 0.5264 & 0.9982 & I. I33 & 0.01936 & $26 \cdot 47$ \\
\hline $2 \mathrm{I}$ & 0.02948 & 0.6191 & 0.6370 & 0.4243 & 0.4122 & $I \cdot 076$ & 0.5578 & $\mathrm{I} \cdot 047$ & I. I97 & 0.02039 & $27 \cdot 89$ \\
\hline 22 & 0.02956 & 0.6503 & 0.6698 & 0.4440 & 0.4313 & $I \cdot I 23$ & 0.5896 & I.095 & $I \cdot 260$ & 0.02142 & $29 \cdot 33$ \\
\hline
\end{tabular}

The column headed v.P. lowering gives the relative pressure lowering $\Delta p / p^{0}=\left(p^{0}-p\right) / p^{0}$, where $p$ is the vapour pressure of the sea water and $p^{0}$ is the vapour pressure of pure water. $p^{0}=23.756 \mathrm{~mm}$ at $25^{\circ} \mathrm{C}$.

isopiestic with sea water. Similar comparisons of $\mathrm{CaCl}_{2}$ with $\mathrm{NaCl}$ (Stokes, I945 a), $\mathrm{MgCl}_{2}$ with $\mathrm{KCl}$ (Robinson \& Stokes, I940; Stokes, $\mathrm{I}_{945}$ b), $\mathrm{MgSO}_{4}$ with $\mathrm{KCl}$ (Robinson \& Jones, I936), $\mathrm{Na}_{2} \mathrm{SO}_{4}$ with $\mathrm{KCl}$ (Robinson, Wilson \& Stokes, I94I), sucrose with $\mathrm{KCl}$ (Robinson \& Sinclair, I934; Scatchard, Hamer \& Wood, I938; Robinson, Smith \& Smith, I942) and urea with $\mathrm{NaCl}$ (Scatchard et al., I938) have been made, enabling us to give in the next six columns of Table II, molalities of various solutions of the same v.P. as sea 
water. The solutions whose concentrations are given in any one row of Table II have the same v.P. and the same (thermodynamic) water activity; it is not claimed that any of them can be mixed without change in V.P. We know little about the v.P. of mixed salt solutions but what information is available suggests that whilst solutions of $\mathrm{NaCl}, \mathrm{KCl}$, and perhaps $\mathrm{CaCl}_{2}$ and $\mathrm{MgCl}_{2}$, can be mixed without significant change in v.P., the admixture of any one of these with $\mathrm{MgSO}_{4}$ may lead to a marked change in V.P.

In the last column but one of Table II are given the v.P. lowerings corresponding to each chlorinity. These can be expressed by the formula

$$
\left(p^{0}-p\right) / p^{0}=0.0009206(\% \mathrm{Cl})+0.00000236(\% \mathrm{Cl})^{2} \text {, }
$$

where $(\% \mathrm{Cl})$ is the chlorinity given in the first column of Table II. The v.P. lowering is therefore not linear in the chlorinity as would appear from the equation of Witting (I908):

$$
p / p^{0}=\mathrm{I}-0.000969(\% \mathrm{Cl}),
$$

an equation which gives a good representation of the vapour-pressure lowering of sea water only in the vicinity of $20 \%$ chlorinity. Thus for standard sea water of $19.386 \% \mathrm{Cl}$, our formula gives $\Delta p / p^{0}=0.01874$, compared with 0.01879 by Witting's formula.

The osmotic pressure, $\Pi$, of these solutions can be calculated by the formula

$$
\Pi=-\left(R T / V_{1}\right) \ln a_{W},
$$

where $V_{1}$ is the partial molal volume of water in the solutions and $a_{W}$ is the water activity or the relative V.P., $p / p^{0}$. It can be assumed without significant error that $V_{1}$ can be equated to the value in pure water; that is to say, it is put equal to the molar volume of pure water. Moreover, the osmotic coefficient, $\phi$, of the solution, defined by

$$
\phi=-(55.5 \mathrm{I} / 2 m) \ln a_{W}
$$

enables us to make the transformation to

$$
\Pi=(2 m R T \phi) /\left(55 \cdot 5 \mathrm{I} V_{1}\right) \text {. }
$$

(The osmotic coefficients of these salt solutions have been tabulated and are easier to use in computations than the quantity $\log a_{W}$; the factor 2 in the above equation is valid for salts dissociating into two ions such as $\mathrm{NaCl}$; for salts like $\mathrm{CaCl}_{2}$ the factor is 3 .)

Substituting numerical values at $25^{\circ}$, this equation becomes

$$
\Pi=48 \cdot 8 m \phi \text {. }
$$

Substituting values of $\phi$ corresponding to the molalities of $\mathrm{NaCl}$ in the third column of Table II and using the tables of osmotic coefficients already evaluated (Robinson, I945; Stokes \& Levien, I946), the osmotic pressures given in the last column of Table II are calculated. They refer to a temperature of $25^{\circ} \mathrm{C}$; at another temperature, $t^{\circ} \mathrm{C}$, the osmotic pressure can be calculated approximately by multiplying by the factor $[\mathrm{I}+(t-25) / 298]$. 
All these experiments refer to $25^{\circ} \mathrm{C}$; none has been done at other temperatures and we can only estimate from other work what the temperature effect is likely to be. One way in which an estimate of the temperature effect can be made is as follows. Thompson (1932) has given a formula for the depression of the freezing-point of sea water:

$$
\Delta T=-0.0966(\% \mathrm{Cl})-0.0000052(\% \mathrm{Cl})^{3},
$$

from which the freezing-point at various chlorinities has been calculated and recorded in Table III. Scatchard \& Prentiss (1933) have measured very accurately the freezing-point of $\mathrm{NaCl}$ solutions, and from their tables we can find by interpolation the molalities of $\mathrm{NaCl}$ solutions which freeze at the same temperature as these sea-water solutions. Solutions of the same freezing-point must have the same v.P. For each of the seven selected chlorinities these $\mathrm{NaCl}$ molalities are also given in the table as well as the corresponding $\mathrm{NaCl}$ molality at $25^{\circ} \mathrm{C}$. It will be seen that the effect of a $26-27^{\circ} \mathrm{C}$ temperature difference corresponds to only a small change in the $\mathrm{NaCl}$ molality, a change of between 0.4 and $0.8 \%$ over a chlorinity range of $10-22 \%$.

\section{TABLE III}

\begin{tabular}{llcccccc}
\multicolumn{1}{c}{$\% \mathrm{Cl}$} & \multicolumn{1}{c}{ I0 } & \multicolumn{1}{c}{ I2 } & \multicolumn{1}{c}{ I4 } & \multicolumn{1}{c}{ I6 } & I8 & 20 & \multicolumn{1}{c}{22} \\
Freezing-point depression & $0.97 \mathrm{I}$ & $\mathrm{I} \cdot \mathrm{I} 68$ & $\mathrm{I} \cdot 366$ & $\mathrm{I} \cdot 567$ & $\mathrm{I} \cdot 769$ & $\mathrm{I} \cdot 974$ & $2 . \mathrm{I} 80$ \\
$\mathrm{M}-\mathrm{NaCl}$ at freezing-point & $0.285 \mathrm{I}$ & 0.3439 & 0.4028 & 0.4627 & 0.5230 & 0.5839 & 0.6450 \\
$\mathrm{M}-\mathrm{NaCl}$ at $25^{\circ}$ & $0.286 \mathrm{I}$ & 0.3452 & 0.4050 & 0.4653 & 0.5263 & 0.5880 & 0.6503
\end{tabular}

Finally we may consider the accuracy which can be attained by calculating the v.P. lowering as the summation of the values for the component salts. We can try the assumption that all the chlorinity can be counted as $\mathrm{NaCl}$ and find the corresponding V.P. lowering. For example, the standard sea water of I9.386\% chlorinity would contain $3 \mathrm{I} \cdot 96 \mathrm{~g} \mathrm{NaCl}$ per $\mathrm{kg}$ of solution calculated on this assumption, equivalent to $0.5648 \mathrm{M}-\mathrm{NaCl}$. Such a solution has a v.P. lowering of $\Delta p / p^{0}=0.01858$ compared with 0.01873 for this sea water (interpolated from Table II). Similarly, the artificial sea water (sample 2) of $20.58 \%$ chlorinity is calculated as $0.6008 \mathrm{M}-\mathrm{NaCl}$ which has $\Delta p / p^{0}=0.01978$ compared with the observed (interpolated) value of 0.01996 , a difference corresponding to only $0.004 \mathrm{~mm}$ of mercury pressure. Alternatively, we could assume that the contribution of each salt is determined by its relative molal v.P. lowering at the total ionic strength of the sea water. For example, the artificial sea water (sample 2), as made up, had the following composition in moles per $\mathrm{kg}$ of $\mathrm{H}_{2} \mathrm{O}$ :

$$
\begin{array}{lllll}
\mathrm{NaCl} & \mathrm{KCl} & \mathrm{MgCl}_{2} & \mathrm{CaCl}_{2} & \mathrm{MgSO}_{4} \\
0.5 \mathrm{I} 25 & 0.0113 & 0.0287 & 0.01 \mathrm{I} 6 & 0.03 \mathrm{I} 5
\end{array}
$$

By taking account of the valencies of these salts the total ionic strength can be calculated as 0.7707 . At this ionic strength the relative molal v.P. lowering 
of each salt can be interpolated from the tables to which reference has already been made, and $\Delta p / m p^{0}$ found to be $0.03300,0.03192,0.04745,0.04652$, 0.02032 for the salts in the order listed above. Hence $\Delta p / p^{0}$ for these salts is $0.01691,0.00036,0.00136,0.00054$ and 0.00064 , and the total is 0.01981 . The mixed solution had a chlorinity of $20.58 \%$, and by interpolation in Table II the relative v.P. lowering is 0.0I996. The difference between 0.0I98I and 0.01996 corresponds to only $0.003 \mathrm{~mm}$ of pressure. In the absence of direct measurements, therefore, the V.P. can be calculated with some confidence either from the v.P. lowering of the component salts or by assuming that sea water is a $\mathrm{NaCl}$ solution of equivalent chlorinity. It is worth while reiterating, however, that the $\mathrm{MgSO}_{4}$ in these solutions is present in comparatively small amount, and the simple additivity rule might not apply so well if this salt were present in large quantities.

I wish to thank Dr L. H. N. Cooper for a number of valuable suggestions and $\mathrm{Mr}$ R. W. Green and Mrs H. Tong for assistance with the analyses.

\section{SUMMARY}

Measurements have been made by the isopiestic method of the vapour pressure at $25^{\circ} \mathrm{C}$ of sea water of chlorinity between ro and $22 \%$. A table is given of the concentrations of solutions of sodium chloride, potassium chloride, calcium chloride, magnesium chloride, magnesium sulphate, sodium sulphate, sucrose and urea of equal vapour pressure to these sea waters. Their osmotic pressures are also tabulated.

\section{REFERENCES}

RoBINson, R. A., I945. The vapour pressures of solutions of potassium and sodium chloride. Trans. roy. Soc. N.Z., Vol. 75, pp. 203-I7.

Robinson, R. A. \& Jones, R. S., I936. The activity coefficients of some bivalent metal sulfates in aqueous solution from vapour pressure measurements. F. Amer. chem. Soc., Vol. 58, pp. 959-61.

Robinson, R. A. \& Sinclair, D. A., I934. The activity coefficients of the alkali chlorides and of lithium iodide in aqueous solution from vapour pressure measurements. F. Amer. chem. Soc., Vol. 56, pp. I830-5.

Robinson, R. A., SMIth, P. K. \& SMITH, E. R. B., I942. The osmotic coefficients of some organic compounds in relation to their chemical constitution. Trans. Faraday Soc., Vol. 38, pp. 63-70.

Robinson, R. A. \& STOKES, R. H., I940. The activity coefficients of magnesium halides at $25^{\circ}$. Trans. Faraday Soc., Vol. 36, pp. 733-4.

Robinson, R. A., Wilson, J. M. \& StOKES, R. H., I94I. The activity coefficients of lithium, sodium and potassium sulfate and sodium thiosulfate at $25^{\circ}$ from isopiestic vapor pressure measurements. F. Amer. chem. Soc., Vol. 63, pp. Ior I-I3.

SCATCHARD, G., HAMER, W. J. \& WOOD, S. E., I938. The chemical potential of water in aqueous solutions of sodium chloride, potassium chloride, sulfuric acid, sucrose, urea and glycerol. F. Amer. chem. Soc., Vol. 60, pp. 306I-70. 
SCAtchard, G. \& Prentiss, S. S., I933. The freezing point of aqueous solutions. IV. Potassium, sodium and lithium chlorides and bromides. F. Amer. chem. Soc., Vol. 55, pp. 4355-62.

Stokes, R. H., I945 a. Properties of calcium chloride solutions up to high concentrations at $25^{\circ}$. Trans. Faraday Soc., Vol. 4I, pp. 637-4I.

I 945 b. Concentrated solutions of magnesium chloride at $25^{\circ}$. Trans. Faraday Soc., Vol. 4I, pp. 642-5.

Stokes, R. H. \& Levien, B. J., I946. The osmotic and activity coefficients of zinc nitrate, zinc perchlorate and magnesium perchlorate. Transference numbers in zinc perchlorate solutions. F. Amer. chem. Soc., Vol. 68, pp. 333-7.

Thompson, T. G., I932. The physical properties of sea water. Physics of the earth. Vol. 5, Oceanography, pp. 63-94. Bull. nat. Res. Coun., Wash., No. 85. [Quoted by H. U. Sverdrup, M. W. Johnson and R. H. Fleming, 1942, The Oceans, New York.]

WITTING, R., I908. Untersuchungen zur Kenntnis den Wasserbewegungen und der Wasserumsetzung in den Finnland umgebenden Meeren. Finnl. hydrogr.-biol. Untersuch., No. 2, p. I73. [Quoted by H. U. Sverdrup, M. W. Johnson and R. H. Fleming, 1942, The Oceans, New York.] 